\title{
AMBIENTE TÉRMICO NO INTERIOR DE MODELOS DE GALPÕES AVÍCOLAS EM ESCALA REDUZIDA COM VENTILAÇÃO NATURAL E ARTIFICIAL DOS TELHADOS
}

\author{
PEDRO A. DOS SANTOS ${ }^{1}$, TADAYUKI YANAGI JUNIOR ${ }^{2}$, VITOR H. TEIXEIRA ${ }^{3}$, \\ LEANDRO FERREIRA ${ }^{4}$
}

RESUMO: O presente trabalho teve o objetivo de avaliar o ambiente térmico no interior de modelos físicos de galpões avícolas construídos em escala reduzida (1:10). O conforto térmico foi avaliado por meio do Indice de Temperatura do Globo Negro e Umidade (ITGU), Carga Térmica de Radiação (CTR) e efetividade das coberturas em reduzir o ITGU em relação à cobertura construída com telhas de alumínio $(\varepsilon)$. Quatro modelos construídos com telhas cerâmicas e equipados com ventilação natural ou forçada foram comparados a dois modelos construídos com telhas cerâmicas e de alumínio, respectivamente, sem lanternim. Pode-se concluir que as coberturas com câmaras de ventilação artificial $\left(\mathrm{B}_{30 \mathrm{CVF}}\right)$ ou natural $\left(\mathrm{B}_{30 \mathrm{CVN}}\right)$ proporcionaram melhores ambientes térmicos no interior dos modelos reduzidos, no qual o último tem a vantagem de não requerer gasto de energia elétrica.

PALAVRAS-CHAVE: cobertura, conforto térmico, avicultura.

\section{THERMAL ENVIRONMENT INSIDE MODELS OF POULTRY HOUSINGS IN REDUCED SCALE WITH NATURAL AND ARTIFICIAL VENTILATED ROOFS}

\begin{abstract}
The goal of the present work was to evaluate the thermal environment inside physical models of broiler housings built in reduced scale (1:10). The thermal comfort was evaluated through the Black Globe Humidity Index (BGHI), Thermal Heat Load (THL) and effectiveness of the roofs in reducing the $\mathrm{BGHI}$ in relation to roofs built with aluminum tiles $(\varepsilon)$. Four models built with ceramic tiles and equipped with natural or forced ventilation were compared to two models built with ceramic and aluminum tiles, respectively, without ridge vent. It was concluded that the roofs with forced $\left(\mathrm{B}_{30 \mathrm{CVF}}\right)$ and natural $\left(\mathrm{B}_{30 \mathrm{CVN}}\right)$ ventilation chamber provided better thermal environments inside the reduced models, in which the last has the advantage of not requesting electric power source.
\end{abstract}

KEYWORDS: covering, thermal comfort, poultry.

\section{INTRODUÇÃO}

Os limites de temperatura da zona de termoneutralidade (ZT) para frangos de corte adultos encontram-se no intervalo de 15 a $25^{\circ} \mathrm{C}$ (CURTIS, 1983; ESMAY \& DIXON, 1986 e TIMMONS \& GATES, 1988), podendo variar em função da sua constituição genética, idade, sexo, tamanho corporal, peso, dieta e exposição prévia ao calor (aclimatação). De acordo com SAINSBURY (1971), YOUSEF (1985) e MEDEIROS (2001), de forma geral, a faixa de temperatura de bulbo seco ( $\mathrm{t}_{\mathrm{bs}}$ ), umidade relativa (UR) e velocidade do ar (V), que resultam em maior desempenho animal, ocorrem entre $21^{\circ} \mathrm{C}$ e $27{ }^{\circ} \mathrm{C} ; 50 \%$ e $70 \%$, e $0,5 \mathrm{~m} \mathrm{~s}^{-1}$ e $1,5 \mathrm{~m} \mathrm{~s}^{-1}$, respectivamente. O desvio do ambiente térmico em relação à ZT resulta em decréscimo produtivo das aves e, em casos extremos, pode levá-las à morte.

\footnotetext{
${ }^{1}$ Eng ${ }^{\circ}$ Agrônomo, Professor, Escola Agrotécnica da UFRR, Boa Vista - RR.

${ }^{2}$ Eng ${ }^{0}$ Agrícola, Professor Adjunto, Departamento de Engenharia, UFLA,Lavras - MG, Fone: (0XX35) 3829.1374, yanagi@ufla.br

${ }^{3}$ Eng ${ }^{\mathrm{o}}$ Agrícola, Professor Adjunto, Departamento de Engenharia, UFLA, Lavras - MG.

${ }^{4}$ Estudante de graduação do Curso de Engenharia Agrícola da UFLA.

Recebido pelo Conselho Editorial em: 23-6-2004

Aprovado pelo Conselho Editorial em: 29-9-2005
} 
Uma das formas de propiciar melhores condições de conforto aos animais, especialmente nas horas mais quentes do dia, é o sombreamento natural ou artificial, que reduz a carga térmica de radiação incidente sobre o animal (BOND et al., 1961; LEAL, 1981; SILVA et al., 1990; SILVA et al., 1991; SEVEGNANI et al., 1994; BAÊTA \& SOUZA, 1997).

BOND et al. (1961) mediram a radiação térmica recebida de várias partes da instalação que envolvia um animal à sombra e concluíram que $28 \%$ da carga térmica de radiação (CTR) provinha do céu, $21 \%$ do material de cobertura, $18 \%$ da área não-sombreada e 33\% da área sombreada. Observa-se, assim, que a CTR, devido ao material de cobertura e sua sombra, representa $54 \%$ da radiação térmica total. Nas condições brasileiras, o sombreamento proveniente de coberturas reduz entre $20 \%$ e $40 \%$ da CTR no interior de instalações para animais (SANTOS et al., 1993; TURCO et al., 1994; ABREU et al., 1995; BAÊTA \& SOUZA, 1997).

Dentre as possíveis estratégias para a redução da CTR no interior de instalações zootécnicas, pode-se fazer uso de diferentes materiais de cobertura (MORAES, 1999), inclinações de telhado (YANAGI JUNIOR et al., 2001), pinturas de telhado (TINÔCO, 2001) e uso de forros (COSTA, 1982; CAMPOS, 1986). Podem-se usar, ainda, a aspersão sobre o telhado (MORAES, 1999) e os telhados ventilados (ZAPPAVIGNA \& LIBERATI, 1997), dentre outras possibilidades.

Para que estudos semelhantes aos citados anteriormente sejam economicamente viáveis, utilizase normalmente dos modelos físicos de galpões avícolas construídos em escala reduzida (MURPHY, 1950; PATTIE \& MILNE, 1966; NEUBAUER, 1972; LEAL, 1981; SILVA et al., 1990; GHELFI FILHO et al., 1991; SEVEGNANI et al., 1994; DANTAS, 1995; MORAES, 1999; JENTZSCH, 2002). Estes estudos baseiam-se na teoria da similitude, que tem por finalidade estabelecer relações que permitam previsões reais, feitas a partir de observações em modelos reduzidos (JENTZSCH, 2002).

Para avaliar e classificar o ambiente térmico no interior de galpões reais ou de modelos físicos construídos em escala reduzida, empregam-se, comumente, o índice de temperatura do globo negro e a umidade (ITGU), a carga térmica de radiação (CTR) e a efetividade $(\varepsilon)$ em relação à cobertura de alumínio.

O ITGU, desenvolvido por BUFFINGTON et al. (1981), é atualmente o índice mais adequado para predizer as condições de conforto térmico em regiões quentes, em razão de incorporar a $t_{b s}, U R, V$ e a radiação na forma de temperatura de globo negro, em um único valor, sendo calculado pela eq.(1):

em que,

$\mathrm{ITGU}=\mathrm{t}_{\mathrm{gn}}+0,36 \mathrm{t}_{\mathrm{po}}-330,08$

$\mathrm{t}_{\mathrm{gn}}$ - temperatura de globo negro, $\mathrm{K}$, e

$\mathrm{t}_{\mathrm{po}}$ - temperatura do ponto de orvalho, $\mathrm{K}$.

Outro índice importante para a avaliação do ambiente térmico é a CTR que, segundo ESMAY (1974), pode ser determinada pela eq.(2):

$\mathrm{CTR}=\sigma\left(\mathrm{T}_{\mathrm{m}}\right)^{4}$

em que,

$\sigma$ - constante de Stefan-Boltzmann $\left(5,67 \times 10^{-8} \mathrm{~W} \mathrm{~m}^{-2} \mathrm{~K}^{-4}\right)$, e

$\mathrm{T}_{\mathrm{m}}$ - temperatura média radiante, calculada pela eq.(3).

$$
\mathrm{T}_{\mathrm{m}}=100\left[2,51 \sqrt{\mathrm{V}}\left(\mathrm{T}_{\mathrm{gn}}-\mathrm{T}_{\mathrm{bs}}\right)+\left(\frac{\mathrm{T}_{\mathrm{gn}}}{100}\right)^{4}\right]^{1 / 4}
$$


Para classificar a diversidade de materiais utilizados nas coberturas e suas concepções, diversos autores têm utilizado o conceito de efetividade $(\varepsilon)$ do material, definida em relação à CTR ou ao ITGU (KELLY \& BOND, 1958; MORAES, 1999; TINÔCO, 2001). Porém, de acordo com MORAES (1999), o uso do ITGU no cálculo da efetividade (ع) [eq.(4)] é mais indicado por ser o índice mais utilizado na quantificação das condições de conforto térmico em instalações zootécnicas.

$$
\varepsilon=\frac{\mathrm{ITGU}_{(\text {ao sol) }}-\mathrm{ITGU}_{\text {(telha testada) }}}{\operatorname{ITGU}_{(\text {ao sol) }}-\mathrm{ITGU}_{\text {(telha de alumínio) }}}
$$

Com base no exposto, este trabalho teve o objetivo de avaliar o ambiente térmico, por meio do ITGU, CTR e $\varepsilon$, no interior de modelos reduzidos físicos de galpões avícolas equipados com telhados natural e artificialmente ventilados, construídos em escala de 1:10.

\section{METODOLOGIA}

Para o desenvolvimento da pesquisa, foram utilizados modelos físicos de galpões para frangos de corte, construídos em escala reduzida, na área experimental do setor de Agrometeorologia e Climatologia do Departamento de Engenharia da Universidade Federal de Lavras, no município de Lavras, durante a estação de verão, nas coordenadas geográficas de $21^{\circ} 14^{\prime} \mathrm{S}$ e de $45^{\circ} 00^{\prime} \mathrm{W}$, a $918 \mathrm{~m}$ de altitude. O clima do município, segundo a classificação climática de Köeppen, é do tipo Cwa, temperado úmido com inverno seco.

\section{Construção dos modelos em escala reduzida}

Foram construídos cinco modelos em escala reduzida 1:10 (MURPHY, 1950; MORAES, 1999) de galpões avícolas com coberturas de telhas cerâmicas do tipo canal e um com telhas de alumínio, totalizando seis tratamentos, conforme indicado na Tabela 1 e nas Figuras 1 e 2.

TABELA 1. Tratamentos testados no experimento.

\begin{tabular}{ll}
\hline Código & \multicolumn{1}{c}{ Descrição dos tratamentos } \\
\hline $\mathrm{B}_{30 \mathrm{CVF}}$ & $\begin{array}{l}\text { Cobertura com telha de cerâmica tipo canal (romana), com pé-direito de } 3,5 \mathrm{~m} \text { e com } 30^{\circ} \\
\text { de inclinação, sem lanternim e com câmara de ventilação forçada paralela à superfície } \\
\text { interna do telhado, construída com lona preta de polietileno. A renovação de ar utilizada } \\
\text { foi de uma troca de ar a cada dois minutos. }\end{array}$ \\
\hline $\mathrm{B}_{30 \mathrm{CVN}}$ & $\begin{array}{l}\text { Cobertura com telha de cerâmica tipo canal (romana), com pé-direito de } 3,5 \mathrm{~m} \text { e } 30^{\circ} \text { de } \\
\text { inclinação, com lanternim e câmara de ventilação natural, construída com lona preta de } \\
\text { polietileno paralela à superfície do telhado. }\end{array}$ \\
\hline $\mathrm{B}_{30 \mathrm{CL}}$ & $\begin{array}{l}\text { Cobertura com telha de cerâmica tipo canal (romana) com } 30^{\circ} \text { de inclinação, com } \\
\text { lanternim e pé-direito de } 3,5 \mathrm{~m} .\end{array}$ \\
\hline $\mathrm{B}_{30 / 40 \mathrm{CL}}$ & $\begin{array}{l}\text { Telhado assimétrico com inclinaçães de } 30^{\circ} \text { norte e } 40^{\circ} \text { sul, com telhas de cerâmica tipo } \\
\text { canal (romana), com lanternim e pé-direito de } 4,0 \mathrm{~m} .\end{array}$ \\
\hline $\mathrm{B}_{30 \mathrm{SL}}$ & $\begin{array}{l}\text { Telha de cerâmica tipo canal (romana) com } 30^{\circ} \text { de inclinação, sem lanternim e pé-direito } \\
3,5 \mathrm{~m} .\end{array}$ \\
\hline $\mathrm{A}_{15 \mathrm{SL}}$ & $\begin{array}{l}\text { Telha de alumínio com } 0,5 \mathrm{~mm} \text { de espessura, com } 15^{\circ} \text { de inclinação, sem lanternim e pé- } \\
\text { direito de } 3,5 \mathrm{~m} .\end{array}$ \\
\hline
\end{tabular}




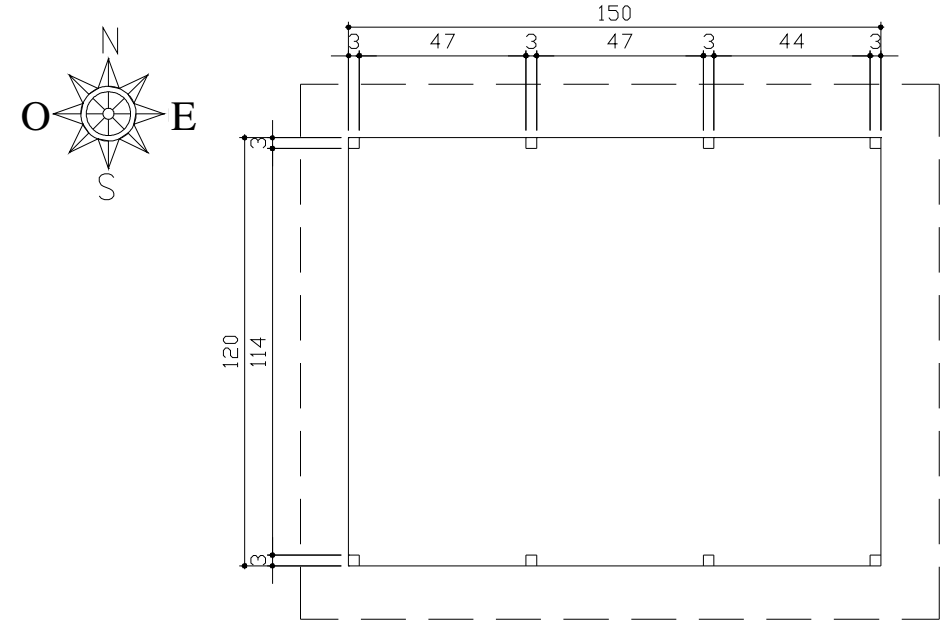

FIGURA 1. Esquema da planta baixa dos modelos físicos em escala reduzida (unidade de cotagem: $\mathrm{cm})$.
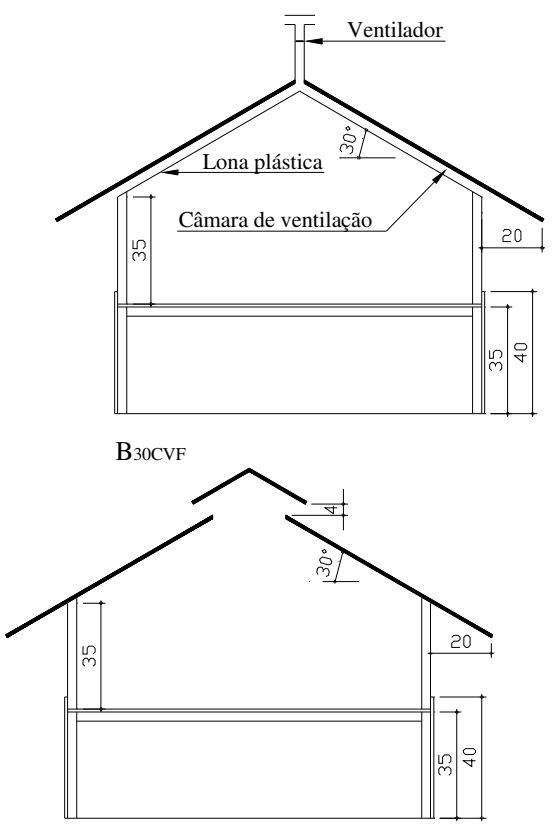

B $30 \mathrm{CL}$

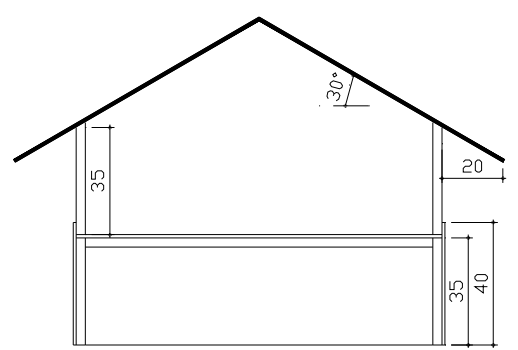

B 30 SL

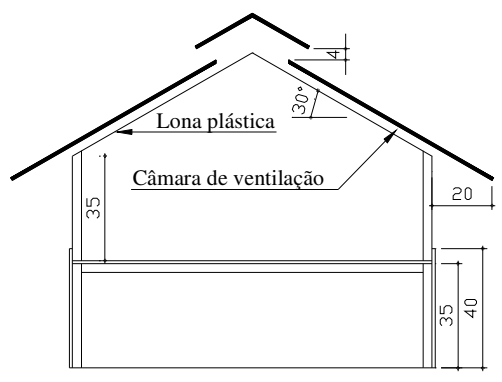

B $30 \mathrm{CVN}$

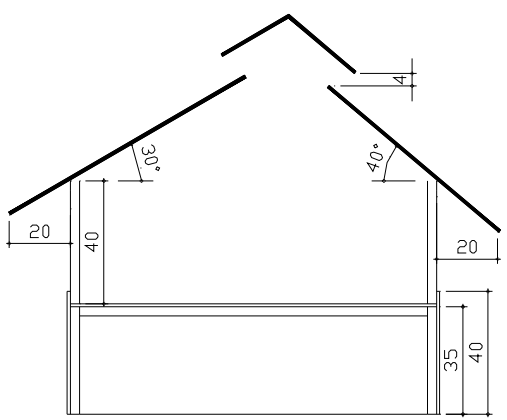

B $30 / 40 \mathrm{CL}$

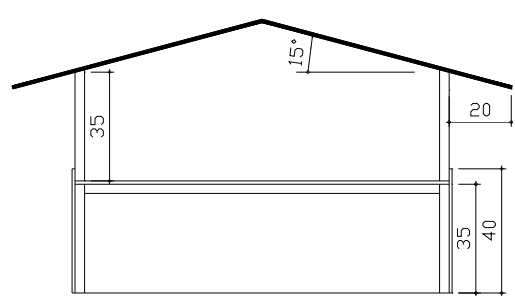

A $15 S L$

FIGURA 2. Esquema das seções transversais dos modelos físicos construídos em escala reduzida (unidade de cotagem: $\mathrm{cm}$ ). 
Na construção dos modelos, utilizou-se como base as dimensões reais de um galpão comercial para criação de frangos de corte, com 12,0 m de largura, 120,0 m de comprimento, pé-direito de 3,5 m e distância entre tesouras de 5,0 m. As águas das coberturas de telhas cerâmicas tinham inclinação de $30^{\circ}$ ou $30^{\circ} / 40^{\circ}\left(\mathrm{B}_{30 / 40 \mathrm{CL}}\right)$ e as de telhas de alumínio $15^{\circ}$, tendo ambas beirais de 2,0 m. Na confecção, foram utilizadas placas de madeira compensada com $1 \mathrm{~cm}$ de espessura, reforçadas por estrutura de madeira com secção de $3 \times 3 \mathrm{~cm}$. Após a construção, os modelos passaram a ter as dimensões de 1,2 m de largura, 1,5 m de comprimento e distância entre tesouras de 0,5 m. As faces leste e oeste dos galpões foram totalmente fechadas com as placas de madeira compensada, enquanto as laterais possuíam altura de $1,5 \mathrm{~cm}$, correspondendo, assim, às muretas de $15 \mathrm{~cm}$ existentes em galpões reais. Os pisos dos galpões foram elevados em relação ao solo em $0,4 \mathrm{~m}$, fazendo com que o fluxo de ar à altura do piso fosse aproximadamente o mesmo com relação a um galpão hipoteticamente real (JENTZSCH, 2002). As cumeeiras dos modelos reduzidos foram orientadas na direção leste-oeste verdadeiro.

\section{Instrumentação e medições no interior e exterior dos modelos em escala reduzida}

Todas as variáveis foram medidas durante um período de dez dias, não consecutivos, em condições de verão, das 8 às $18 \mathrm{~h}$, em intervalos de $30 \mathrm{~min}$. Porém, devido à alta nebulosidade que ocorreu durante as duas primeiras horas e as duas últimas horas de medição, utilizou-se dos dados medidos das 10 às $16 \mathrm{~h}$, em que o céu se encontrava com pouca ou nenhuma nebulosidade e que coincide com os valores de ITGU que caracterizam desconforto térmico.

Para a medição das $t_{\mathrm{bs}}$, temperatura de bulbo úmido $\left(\mathrm{t}_{\mathrm{bu}}\right)$ e $\mathrm{t}_{\mathrm{gn}}$, utilizou-se de um termômetro digital para sensor termopar tipo $\mathrm{T}$ (precisão de $\pm 0,02{ }^{\circ} \mathrm{C}$ ). $\mathrm{O}$ termômetro de globo negro foi construído com uma esfera de plástico com $3,6 \mathrm{~cm}$ de diâmetro, sendo pintada de preto-fosco. Os sensores foram instalados na altura correspondente ao centro geométrico de massa das aves, ou seja, a $3 \mathrm{~cm}$ do piso (correspondendo a $30 \mathrm{~cm}$ em galpões reais).

A velocidade do ar foi medida por meio de um anemômetro digital com precisão de $\pm 0,10 \mathrm{~m} \mathrm{~s}^{-1}$, sendo as medidas obtidas nas proximidades de cada globo negro, nos mesmos dias e horários considerados.

Os dados climáticos externos foram coletados no interior de um abrigo meteorológico, instalado na área experimental. Nesse abrigo, foram instalados sensores para a medição da $t_{b s}$ e $t_{b u}$ durante toda a fase experimental. Um termômetro de globo negro foi instalado no ambiente externo, possibilitando, assim, a determinação do ITGU e da CTR. A velocidade do ar foi medida conforme citado anteriormente.

\section{Determinação dos índices térmicos e da efetividade}

A partir dos dados de $t_{\mathrm{bs}}, \mathrm{t}_{\mathrm{bu}}, \mathrm{t}_{\mathrm{gn}} \mathrm{e} \mathrm{V}$ medidos nos horários predeterminados, foram calculados os valores respectivos de ITGU e CTR para cada horário de medição, de acordo com as eq.(1) e (2), respectivamente. A efetividade de cada modelo testado foi calculada em função dos valores de ITGU correspondente ao nível das aves, para cada tratamento, ao sol e padrão (telha de alumínio), nos horários de 10 às $16 \mathrm{~h}$, conforme eq.(4).

\section{Delineamento experimental e análise estatística}

Utilizou-se do delineamento em blocos casualizados (DBC), no qual os tratamentos foram dispostos em esquema de parcelas subdivididas, com dez repetições (dias de medição), atribuindo às parcelas os modelos construídos em escala reduzida com as diversas coberturas natural e artificialmente ventiladas, e às subparcelas, os horários de medição. As médias de ITGU e CTR para os tratamentos foram comparadas pelo teste de Skott-Knott, a 5\% de probabilidade. 


\section{RESULTADOS E DISCUSSÃO}

O resumo das análises de variância para as variáveis-resposta ITGU e CTR (W m ${ }^{-2}$ ), correspondente aos tratamentos e horários de medição, é mostrado na Tabela 2. Verifica-se que, tanto para o ITGU, quanto para a CTR, houve diferença significativa $(\mathrm{p}<0,01)$ para os fatores tratamentos e horários de medição. Porém, não foi verificada diferença significativa para a interação tratamento $\mathrm{x}$ horários $(\mathrm{p}>0,05)$. Os coeficientes de variação para a parcela e subparcela foram de 1,27\% e 1,21\%, respectivamente, e para o ITGU de 0,85\% e 1,39\% para a CTR, demonstrando pouca variabilidade dos valores observados em relação as médias.

TABELA 2. Resumo das variâncias referentes ao efeito dos tratamentos (telhados natural e artificialmente ventilados) à altura de medição do centro de massa das aves e aos horários de observação.

\begin{tabular}{lccc}
\hline \multicolumn{1}{c}{ FV } & \multirow{2}{*}{ GL } & \multicolumn{2}{c}{ Quadrados Médios } \\
\cline { 2 - 4 } & & \multicolumn{1}{c}{ ITGU } & CTR \\
\hline Blocos & 9 & $365,22^{* * *}$ & $7.045,13^{* *}$ \\
Tratamentos & 5 & $22,59^{* *}$ & $1.648,76^{* *}$ \\
Erro (a) & 45 & 1,04 & 16,75 \\
Horário & 12 & $345,98^{* *}$ & $13.386,50^{* *}$ \\
Tratamentos x horários & 60 & $0,53^{\text {ns }}$ & $16,67^{\text {ns }}$ \\
Erro (b) & 648 & 0,94 & 45,22 \\
C.V. erro (a) - \% & & 1,27 & 0,85 \\
C.V. erro (b) - \% & & 1,21 & 1,39 \\
\hline
\end{tabular}

significativo a $1 \%$ de probabilidade; ${ }^{\text {ns }}$ não significativo.

Quanto ao ITGU, de acordo com a Tabela 3, as melhores condições térmicas no interior dos modelos em escala reduzida foram observadas nos tratamentos $B_{30 C V F}$ e $B_{30 C v N}$, que são estatisticamente diferentes (teste Skott-Knott, $\mathrm{p}<0,05$ ). Os valores intermediários foram observados para os tratamentos $B_{30 C L}$ e $B_{30 / 40 C L}$ que apresentaram resultados estatisticamente iguais (teste SkottKnott, p > 0,05).

TABELA 3. Valores médios e desvios-padrão do índice de temperatura do globo negro e umidade (ITGU), carga térmica de radiação (CTR) e efetividade $(\varepsilon)$ determinados para os tratamentos testados (Tabela 1).

\begin{tabular}{cccc}
\hline Tratamentos & ITGU & CTR $\left(\mathrm{W} \mathrm{m}^{-2}\right)$ & $\varepsilon$ \\
\hline $\mathrm{B}_{30 \mathrm{CVF}}$ & $79,36 \pm 3,20 \mathrm{a}$ & $480 \pm 17 \mathrm{a}$ & $1,11 \pm 0,04$ \\
$\mathrm{~B}_{30 \mathrm{CVN}}$ & $79,74 \pm 3,14 \mathrm{~b}$ & $480 \pm 17 \mathrm{a}$ & $1,10 \pm 0,05$ \\
$\mathrm{~B}_{30 \mathrm{CL}}$ & $80,02 \pm 3,34 \mathrm{c}$ & $481 \pm 18 \mathrm{a}$ & $1,09 \pm 0,05$ \\
$\mathrm{~B}_{30 / 40 \mathrm{CL}}$ & $80,03 \pm 3,12 \mathrm{c}$ & $485 \pm 18 \mathrm{~b}$ & $1,08 \pm 0,06$ \\
$\mathrm{~B}_{30 \mathrm{SL}}$ & $80,28 \pm 3,29 \mathrm{~d}$ & $487 \pm 18 \mathrm{c}$ & $1,05 \pm 0,03$ \\
$\mathrm{~A}_{15 \mathrm{SL}}$ & $80,56 \pm 3,35 \mathrm{e}$ & $487 \pm 19 \mathrm{c}$ & 1,00 \\
\hline
\end{tabular}

Médias seguidas da mesma letra, nas colunas, para ITGU e CTR, não diferem entre si pelo teste de Scott-Knott, a 5\% de probabilidade.

Nota-se que as modificações propostas no tratamento $\mathrm{B}_{30 / 40 \mathrm{CL}}$ não contribuíram positivamente na melhoria do ambiente térmico em relação ao tratamento $\mathrm{B}_{30 \mathrm{CL}}$. Possivelmente, isso se deve à maior altura do pé-direito $(0,4 \mathrm{~m}$, correspondente a $4 \mathrm{~m}$ em galpão real) que propiciou maior exposição do interior do galpão à CTR proveniente do ambiente externo. As piores condições térmicas foram observadas nos tratamentos $\mathrm{B}_{30 \mathrm{SL}}$ e $\mathrm{A}_{15 \mathrm{SL}}$ que são estatisticamente diferentes (teste Skott-Knott, 
p < 0,05). Com relação à CTR (Tabela 3), os tratamentos que apresentaram melhores ambientes térmicos foram $\mathrm{B}_{30 \mathrm{CVF}}, \mathrm{B}_{\mathrm{CVN}}$ e $\mathrm{B}_{30 \mathrm{CL}}$, que são estatisticamente iguais (teste Skott-Knott, $\mathrm{p}>0,05$ ), sendo seguidos pelos tratamentos $\mathrm{B}_{30 / 40 \mathrm{CL}}, \mathrm{B}_{30 \mathrm{SL}}$ e $\mathrm{A}_{15 \mathrm{SL}}$, sendo os dois últimos estatisticamente iguais (teste Skott-Knott, $\mathrm{p}>0,05$ ).

No geral, verificou-se que a adoção de câmara de ventilação forçada ou natural, na região da cobertura, proporcionou melhores ambientes térmicos (tratamentos $\mathrm{B}_{30 \mathrm{CVF}}$ e $\mathrm{B}_{\mathrm{CVN}}$, respectivamente) no interior dos modelos físicos de galpões avícolas construídos que nos demais tratamentos. Portanto, pode-se inferir que a camada de ar é um bom isolante térmico em condições de altas temperaturas e que a alternativa de renovar o ar aquecido é um recurso que pode ser utilizado para amenizar o desconforto térmico nos ambientes, em períodos de altas temperaturas, desde que os custos sejam compensatórios, confirmando os resultados obtidos por GHELFI FILHO et al. (1991).

As maiores efetividades foram observadas para os tratamentos $\mathrm{B}_{30 \mathrm{CVF}}$ e $\mathrm{B}_{30 \mathrm{CVN}}$, que foram de 1,11 e 1,10, respectivamente. Embora a superfície negra do filme de polietileno usado como forro possua efeitos indesejáveis, tais como maior temperatura da superfície, maior emissividade e absortividade, tem a vantagem de possuir baixa refletividade (TINÔCO, 2001).

Essa baixa refletividade, possivelmente, proporcionou baixas temperaturas do termômetro de globo negro, ocasionando valores menores de ITGU. Em ambos os tratamentos $\left(\mathrm{B}_{30 \mathrm{CVF}}\right.$ e $\mathrm{B}_{30 \mathrm{CVN}}$ ), houve a formação de camada isolante de ar entre forro e telhado, o que também atuou de forma a diminuir a $t_{g n}$ e, conseqüentemente, diminuir o ITGU e a CTR em relação aos demais tratamentos, traduzindo-se, assim, em melhores condições de conforto nos ambientes internos.

Nas Figuras 3 e 4, apresenta-se o comportamento médio do ITGU e da CTR em função dos horários de medição, cuja interação não foi significativa (teste F, p > 0,05).

A redução média da CTR, devido ao sombreamento proveniente das coberturas, foi de $30 \pm 4 \%$ (Figura 4), estando de acordo com os valores encontrados por outros autores (SANTOS et al., 1993; TURCO et al., 1994; ABREU et al., 1995; BAÊTA \& SOUZA, 1997), enquanto a redução do ITGU foi de $10 \pm 1,5 \%$, amenizando, assim, os efeitos indesejáveis das adversidades climáticas, principalmente da radiação solar.

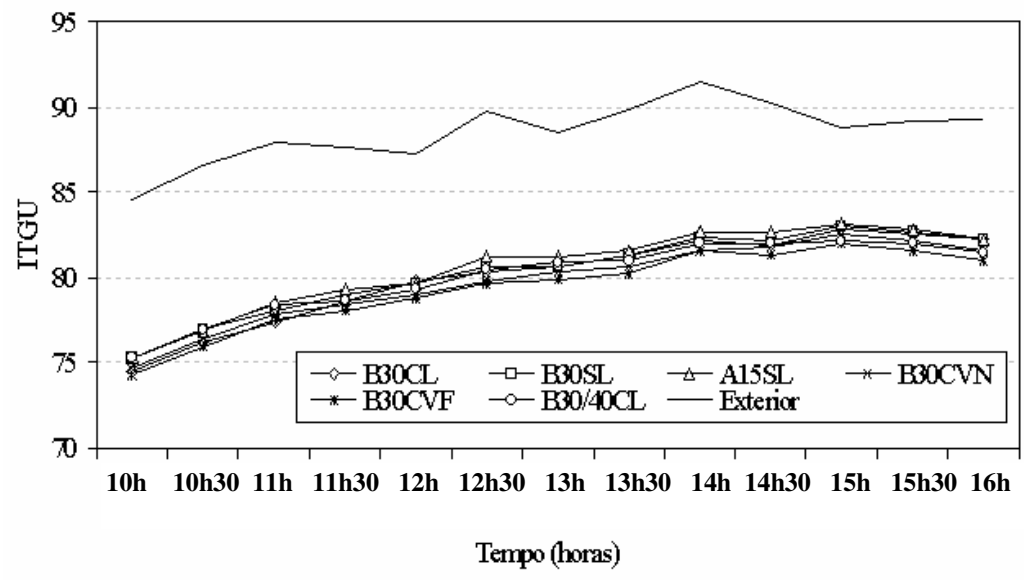

FIGURA 3. Médias de índice de temperatura do globo negro e umidade (ITGU), correspondente ao nível das aves, em função dos horários de observações. 


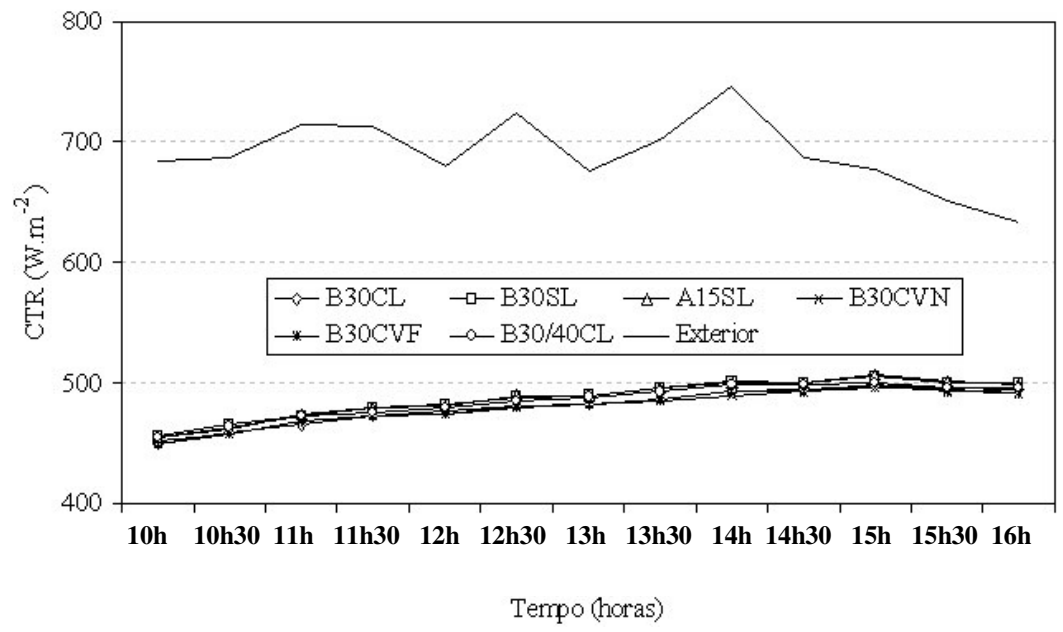

FIGURA 4. Médias de carga térmica de radiação (CTR), correspondente ao nível das aves, em função dos horários de medição.

\section{CONCLUSÕES}

Com base no índice de temperatura de globo negro e umidade (ITGU), carga térmica de radiação $(\mathrm{CTR})$ e efetividade $(\varepsilon)$, o tratamento que proporcionou as melhores condições térmicas no interior dos modelos físicos de galpões avícolas, construídos em escala reduzida, foi o $\mathrm{B}_{30 \mathrm{CVF}}$. $\mathrm{O}$ segundo melhor tratamento foi o $\mathrm{B}_{30 \mathrm{CVN}}$. Apesar de ocupar a segunda colocação, o uso do $\mathrm{B}_{30 \mathrm{CVN}}$ é atrativo quando comparado ao tratamento $\mathrm{B}_{30 \mathrm{CVF}}$, pois independe do uso de energia elétrica. Valores intermediários de ITGU, CTR e $\boldsymbol{\varepsilon}$ foram obtidos para os tratamentos $\mathrm{B}_{30 \mathrm{CL}}$ e $\mathrm{B}_{30 / 40 \mathrm{CL}}$.

Apesar de as modificações propostas não garantirem condições de conforto térmico no interior dos modelos físicos de galpões avícolas construídos em escala reduzida (1:10), durante as horas mais quentes do dia, essas podem e devem ser usadas como forma de reduzir os gastos com sistemas de ventilação e resfriamento evaporativo.

\section{REFERÊNCIAS}

ABREU, P.G.; BAÊTA, F.C.; SOARES, A.R.; ABREU, U.M.N.; MACIEL, N.F. Utilização de piso aquecido eletricamente na criação de aves. Engenharia na Agricultura, Viçosa, v.4, n.12, p.1-19, 1995.

BAÊTA, F.C.; SOUZA, C.F. Ambiência em edificações Rurais: conforto térmico animal. Viçosa: UFV, 1997. 246 p.

BOND, T.E.; KELLY, C.F.; GARRET, W.N.; HAHN, L. Evaluation of materials for livestock shades. California Agriculture, Berkeley, v.15, n.1, p.7-8, 1961.

BUFFINGTON, D.E.; COLLASSO-AROCHO, A.; CANTON, G.H.; PIT, D. Black globe-humidity index (BGHI) as comfort equation for dairy cows. Transactions of the ASAE, St. Joseph, v.24, n.3, p.711-14, 1981.

CAMPOS, A.T. Determinação de índices de conforto térmico e da carga de térmica radiação em quatro tipos de galpões, em condições de verão para Viçosa. 1986. 66 f. Dissertação (Mestrado em Construções Rurais e Ambiência) - Universidade Federal de Viçosa, Viçosa, 1986.

COSTA, E.C. Arquitetura ecológica, condicionamento térmico natural. São Paulo: Edgard Blücher, 1982. $264 \mathrm{p}$. 
CURTIS, S.E. Environmental management in animal agriculture. Ames: The Iowa State University, 1983. $410 \mathrm{p}$.

DANTAS, F.F. Estudo do termossifão em galpões para frangos de corte com cobertura em telhas de cerâmica e de cimento-amianto.1995. 48 f. Dissertação (Mestrado em Construções Rurais e Ambiência) - Universidade Federal de Viçosa, Viçosa, 1995.

ESMAY, M.L. Principles of animal environment. $2^{\text {nd }}$. West Port: AVI, 1974. 325 p.

ESMAY, M.L.; DIXON, J.E. Environmental control for agricultural buildings. West Port: AVI, 1986. $287 \mathrm{p}$.

GUELFI FILHO, H.; SILVA, I.J.O.; MOURA, D.J.; CONSIGLIERO, F.R. Índices de conforto térmico e da CTR para diferentes materiais de cobertura em 3 estações do ano. In: CONGRESSO BRASILEIRO DE ENGENHARIA AGRÍCOLA, 20., 1991, Londrina. Anais... Londrina: Sociedade Brasileira de Engenharia Agrícola, 1991. v.1, p.94-113.

JENTZSCH, R. Estudos de modelos reduzidos destinados à predição de parâmetros térmicos ambientais em instalações agrícolas. 2002. 103 f. Tese (Doutorado em Construções Rurais e Ambiência) - Universidade Federal de Viçosa, Viçosa, 2002.

KELLY, C.F.; BOND, T.E. Effectiveness of artificial shade materials. Agriculture Engineering, St. Joseph, v.39, n.12, p.758-9, 764, 1958.

LEAL, P.A.M. Determinação do microclima gerado dentro de uma estrutura a partir de dados ambientais. 1981. 79 f. Tese (Mestrado em Construções Rurais e Ambiência) - Universidade Estadual de Campinas, Campinas, 1981.

MEDEIROS, C.M. Ajuste de modelos e determinação de índice térmico ambiental de produtividade para frangos de corte. 2001. 115 f. Tese (Doutorado em Construções Rurais e Ambiência) Universidade de Federal de Viçosa, Viçosa, 2001.

MORAES, S.R.P. Conforto térmico em modelos reduzidos de galpões avícolas, para diferentes coberturas, durante o verão. 1999. 73 f. Dissertação (Mestrado em Construções Rurais e Ambiência) - Universidade Federal de Viçosa, Viçosa, 1999.

MURPHY, G.C.E. Similitude in engineering. New York: Ronal Press, 1950. 302 p.

NEUBAUER, L.W. Optimum alleviation of solar stress on model buildings. Transactions of the $A S A E$, St. Joseph, v.15, n.1, p.129-32, 1972.

PATTIE, D.R.; MILNE, W.R. Ventilation air-flow patterns by use of models. Transactions of the $A S A E$, St. Joseph, v.9, n.5, p.646-9, 1966.

SAINSBURY, D. Sanidad y alojamientos para animales. Barcelona: Ed. Continental, 1971. 196 p. SANTOS, A.C.; BAÊTA, F.C.; CECON, P.R.; CARDOSO, R.M. Análise de diferentes bezerreiros individuais móveis, para região de Viçosa. Engenharia na Agricultura, Viçosa, v.2, n.7, p.1-8, 1993.

SEVEGNANI, K.B.; SILVA, I.J.O.; GHELFI FILHO, H. Comparação de vários materiais de cobertura através dos índices de conforto térmico. Scentia Agrícola, Piracicaba, v.51, n.1, p.1-7, 1994.

SILVA, I.J.O.; GHELFI FILHO, H.; CONSGLIERO, F.R. Influência dos materiais de cobertura no conforto térmico de abrigos. Engenharia Rural, Piracicaba, v.1, n.2, p. 43-55, 1991.

SILVA, I.J.O.; GHELFI FILHO, H.; CONSGLIERO, F.R. Materiais de cobertura para instalações animais. Engenharia Rural, Piracicaba, v.1, n.1, p.51-60, 1990. 
TIMMONS, M.B.; GATES, R.S. Predictive model of laying hen performance to air temperature and evaporative cooling. Transactions of the ASAE, St. Joseph, v.31, n.5, p.1503-9, 1988.

TINÔCO, I.F.F. Avicultura industrial: novos conceitos de materiais, concepções e técnicas construtivas disponíveis para galpões avícolas brasileiros. Revista Brasileira de Ciências Avícolas, Campinas, v.3, n.1, p.1-26, 2001.

TURCO, S.H.N.; BAÊTA, F.C.; COSTA, P.M.A.; CARDOSO, R.M.; CECON, P.R. Modificações das condições ambientais de verão em maternidades de suínos. Engenharia na Agricultura, Viçosa, v.3, n.11, p.1-12, 1994.

YANAGI JUNIOR, T.; DAMASCENO, G.S.; TEIXEIRA, V.H.; XIN, H. Prediction of black globe humidity index in poultry buildings. In: INTERNATIONAL LIVESTOCK ENVIRONMENT

SYMPOSIUM, 6., 2001, Louisville. Proceedings... Louisville: ASAE, 2001. p.482-9.

YOUSEF, M.K. Stress physiology in livestock. Poultry Science, Boca Raton, v.3, p.159, 1985.

ZAPPAVIGNA, P.; LIBERATI, P. Towards a more comprehensive approach to the environmental control in hot climate. In: INTERNATIONAL SYMPOSIUM LIVESTOCK ENVIRONMENT, 5., 1997, Bloomington. Proceedings... Bloomington: ASAE, 1997. p.686-93. 